\title{
O PROCESSO DE GLOBALIZAÇÃO, SUA INTERFACE COMA CULTURA E A COMUNICAÇÃO
}

CAMPOS, Renato Márcio Martins de. Docente do Departamento de Ciências Humanas e Sociais do Centro Universitário de Araraquara - Uniara. Docente da Universidade de Ribeirão Preto - Unaerp. Especialista em

Teorias e Técnicas da Comunicação Social. Mestre em Comunicação e Mercado pela Faculdade de

Comunicação Social Cásper Líbero. End.: Rua Arnaldo Victaliano, 1800 - Bloco Sevilha, Ap.42 - Ribeirão Preto, SP. Cep: 14091-220. E-mail: renatodecampos@yahoo.com.br.

\section{RESUMo}

Este trabalho aborda como e em que pontos o processo de globalização implementa influências em nosso cotidiano, destacando-se os lados positivos e negativos resultantes dessa intervenção. Além disso, também se foca a cultura de massa, enfatizando seus efeitos e importância tanto econômica e social quanto política e ideológica dentro do nosso cenário atual.

Palavras-chave: Indústria cultural; Cultura da mídia; globalização.

\section{Abstract}

This work discusses how and in which points and ways the globalization process influences our daily life, pointing out the final positive and negative sides resulting from this intervention. Besides, it also focuses on the mass culture, emphasizing its effects and importance to the economic and social aspects as well as to the political and ideological ones in our current context.

KEYwORDs: Cultural industry; Media culture; Globalization. 
O presente artigo é a base teórica de uma pesquisa intitulada: "O Conceito de Cultura da Mídia, Indústria Cultural e Produção de Entretenimento no Brasil - Sua empregabilidade através do caso Ônibus 174" em desenvolvimento no Centro Universitário de Araraquara - Uniara, que conta com o fomento da Fundação Nacional de Desenvolvimento do Ensino Superior Particular - Funadesp, cuja continuidade será a seleção e análise de material midiático para aplicação e interpretação de tais obras sob as luzes dos conceitos apresentados a seguir.

A sociedade contemporânea é cada vez mais influenciada e dependente das atividades midiáticas, já que estas, muitas vezes, estão disponíveis e acessíveis em momentos significativos de lazer e cultura. $\mathrm{O}$ fato é: até que ponto a mídia atua como agente manipulador das massas? Ao mesmo tempo em que as produções sociais criticam o sistema atual estabelecido, estão extremamente ligadas a tal ato de domínio, como se a busca pela audiência abrisse um leque de opiniões e críticas, mas que ao menos fosse atingida.

Apresentar e discutir aspectos culturais inseridos na mídia pode parecer um assunto amplo e de difícil acesso; entretanto, a facilitação da circulação de informações e entretenimento que acontece em nosso cotidiano possibilita o estudo e ainda mais: facilita o acesso aos dados necessários a tal proposta de pesquisa científica.

A circulação de informações e entretenimento acima referida é uma das características centrais do processo de globalização que se acentuou e foi determinante de nossa realidade, principalmente a partir da década de 90. Convém, portanto, para o entendimento e desenvolvimento deste artigo, pontuar aspectos centrais que envolvem a globalização, a cultura, o processo de indústria cultural e o conceito de cultura da mídia.

A globalização passou a ser um termo bastante utilizado em nosso cotidiano e, por isso, carece desde já de uma definição que delimite seu universo de atuação, e facilite a demarcação em seu campo cultural, conforme se apresenta a seguir:

Trata-se de um processo complexo que atravessa as mais diversas áreas da vida social, da globalização dos sistemas produtivos e financeiros à revolução das tecnologias e práticas de informação e comunicação, da erosão do Estado nacional e redescoberta da sociedade civil ao aumento exponencial das desigualdades sociais, das grandes movimentações fronteiriças de pessoas como imigrantes, turistas ou náufragos, ao protagonismo das empresas multinacionais e das instituições financeiras multilaterais, das novas práticas culturais e identitárias aos estudo de consumo globalizado (SANTOS, 2002, p.11).

A partir dessa definição se percebe a presença de algumas vertentes principais no modus operandi do processo de globalização, por exemplo, a questão econômica, dentre outros importantes elementos. Por tratar-se de um período em que o processo econômico preponderante entre as nações é o da economia de mercado, sob a égide do neoliberalismo, é natural que ocorra uma intensificação entre as nações do processo de trocas dentro do setor. Essas trocas acontecem em diferentes áreas de atuação e conhecimento do homem, como a produção de bens e serviços, os mercados financeiros, a construção e disseminação da informação e entretenimento. Não se pode esquecer que todo esse processo engloba a produção, distribuição e consumo dos itens acima referenciados. Daí a presença de empresas globais nos mais diferenciados mercados e segmentos econômicos conhecidos.

O processo, que extrapola as fronteiras nacionais, fortalece o que se pode chamar de sociedade global: "a existência de processos globais que transcendem os grupos, as classes sociais e as nações. Ele tem como hipótese a emergência de uma sociedade global" (ORTIZ, 2000, p.7).

A sociedade global pressupõe uma área de atuação maior que a questão econômica e as relações entre mercados. Daía necessidade de se pontuar o processo de globalização como algo mais amplo e abrangente que a simples atuação de empresas em caráter global. Mesmo porque uma série de interferências culturais acontece quando se liberam as amarras da distribuição 
de informações e entretenimento entre as nações.

Internacionalização refere-se simplesmente ao aumento da extensão geográfica das atividades econômicas através das fronteiras nacionais; isso não é um fenômeno novo. A globalização da atividade econômica é qualitativamente diferente. Ela é uma força mais avançada, e complexa, da internacionalização, implicando certo grau de integração funcional entre as atividades econômicas dispersas. O conceito se aplica, portanto, à produção, distribuição e consumo de bens e de serviços, organizados a partir de uma estratégia mundial, e voltada para um mercado mundial. Ele corresponde a um nível e a uma complexidade da história econômica no qual as partes, antes inter-nacionais, se fundem agora numa mesma síntese: o mercado mundial (ORTIZ, 2000, p.15,16).

O processo de globalização, quando encarado a partir da questão das interferências culturais, conduz a algumas características básicas que, de certa forma, permitiram sua implementação em nosso cotidiano. Dentre essas características se podem destacar o avanço da tecnologia e da comunicação, a formação de grandes blocos econômicos, a queda de barreiras alfandegárias e de fronteira entre diversos países, o deslocamento das atividades fabris para regiões com mão de obra mais barata. Ortiz pontua tais características ao evidenciar várias obras ligadas à contextualização do processo de globalização:

Chama a atenção nesses textos a profusão de metáforas utilizadas para descrever as transformações do final de século: "Primeira Revolução Mundial" (Alexander King); "Terceira Onda" (Alvin Toffler); "Sociedade Informática" (Adam Shaff); "Sociedade Amébica" (Kenichi Ohmae); "Aldeia Global" (Mcluhan). Fala-se da passagem de uma economia de high volume para outra de high value (Robert Reich), e da existência de universo habitado por "Objetivos
Móveis" (Jacques Attali), deslocando-se incessantemente de um canto para o outro do planeta (ORTIZ, 2000, p.14).

Assim, o processo de globalização configura-se com aspectos positivos e negativos, dentre os quais se evidenciam alguns. Por um lado, o avanço da tecnologia e da comunicação determinou várias novas comodidades aos indivíduos da sociedade global. Por outro, provocou a alteração de comportamentos e a quebra de valores culturais antes arraigados nas sociedades em termos regionais e locais. Por exemplo, a tecnologia da comunicação hoje nos proporciona acesso praticamente sem limites a informações e entretenimento, através do que talvez seja o ícone maior deste processo: a internet. Por meio dessa verdadeira rede ou teia de informações se tem acesso a dados culturais ou acadêmicos de praticamente todo o mundo, a pesquisas e a publicações acadêmicas antes circunscritas em seus universos de produção; se podem intercambiar informações, conversas ou participar de comunidades virtuais, as redes sociais. Enfim, as informações e o entretenimento estão cada vez mais disponíveis através das novas tecnologias de comunicação. Na contramão da tendência, ou o que se poderia evidenciar como aspecto negativo das inovações tecnológicas, está a disseminação de conteúdo pornográfico e de exploração sexual infantil, atualmente facilitada pela tecnologia da comunicação.

No cenário histórico e político, o processo de globalização pontua novas disputas mesmo em âmbito interno dos países e emerge como fruto de uma espécie de nova ordem mundial, a partir da queda de todo o bloco socialista, antes conhecido como segundo mundo:

A derrubada do Muro de Berlim, a queda do império comunista soviético e a dissolução final da própria União Soviética pareciam por fim ao pesadelo. O resultado, porém, não foi a criação de uma nova era de paz e estabilidade. Em vez disso, explodiram guerras nacionalistas e religiosas, criando uma nova era de medo e instabilidade, sem forças políticas capazes de 


\section{O processo de globalização, sua interface...}

oferecer uma via atraente para se sair do pantanal de recessão econômica, da instabilidade política e da confusão cultural. Nos Estados Unidos também se intensificaram as guerras culturais, em que os assaltos direitistas ao politicamente correto funcionaram como arma de ataque às forças e as ideias progressistas (KELLNER, 2001, p.26).

Em termos de aproximação entre nações podem-se evidenciar, como aspectos principais, a formação de blocos econômicos que facilitaram o comércio e a disseminação das tecnologias e das indústrias em diversos países, antes tidos como subdesenvolvidos e com economias precárias. $\mathrm{O}$ lado negativo desse aspecto acontece quando se evidencia as disputas comerciais entre os países desenvolvidos e os países em desenvolvimento: os subsídios determinados por diversos países em seus setores de produção agrária ou mineral constituem grandes barreiras a uma integração econômica em escala verdadeiramente mundial. $\mathrm{O}$ protecionismo em setores estratégicos ainda é um empecilho à integração igualitária entre os países que concentram suas economias em produção agrária e mineral e os países que focam em indústria e tecnologia. Deve-se evidenciar também que a queda de barreiras de controle entre os países facilitou o tráfico de drogas, de informações e de produtos, pois diminuiu a possibilidade de controle do Estado sobre essas áreas.

Cabe ainda ressaltar que o deslocamento das atividades fabris para outros mercados, ainda que determinem certo nível de desenvolvimento local, o fazem, muitas vezes, através de denúncias de exploração do trabalho infantil ou de mulheres, dentre outras possibilidades que colaboram para uma baixa remuneração da mão de obra e tiram vantagens da falta de organização trabalhista desses locais ou regiões.

Os governos do Ocidente, majoritariamente a favor de liberdade na economia, levantaram esse dogma como diretriz de sua política no decorrer da década de 1980. Desregulamentação ao invés de controle pelo Estado, liberalização do comércio e do fluxo de capitais, bem como privatização das empresas estatais, tornaram-se armas estratégicas no arsenal de governos crentes na economia de mercado e no das organizações por eles orientadas: Banco Mundial, Fundo Monetário Internacional, Organização Mundial do Comércio (MARTIN; SCHUMANN, 1998, p.18).

Ante a esse panorama global, o aspecto cultural também sofreu transformações: muitas vezes a transposição das barreiras entre regiões ou países causaram choques culturais, verdadeiros movimentos de xenofobia sob o manto da cultura ou da religião levaram a conflitos, segregações e culminaram com ações violentas entre os grupos envolvidos. Talvez uma das maiores mostras desse aspecto seja mesmo os ataques terroristas ao World Trade Center, nos Estados Unidos, em novembro de 2001. Adefinição da questão da cultura se faz necessária, justamente, para evidenciar um paradigma do mundo em processo de globalização - o planeta ficou menor, mas não menos diverso.

O posicionamento a respeito de cultura adotado neste trabalho se aproxima da visão ampla demonstrada a partir da seguinte citação:

O termo cultura pretende ser entendido aqui como "a produção de fenômenos que contribuem, mediante a representação ou reelaboração simbólicas das estruturas materiais, para compreensão, reprodução ou transformação do sistema social... todas as práticas e instituições dedicadas à administração, renovação e reestruturação do sentido" (CANCLINI, 1983, p. 29). (...) Além de representar a sociedade, a cultura cumpre a função de reelaborar as estruturas sociais e imaginar outras, como necessidade de produção de sentido (GERALDO, 2006, p.03).

Tal observação evidencia a complexidade do fator cultural e sua interseção perante a organização da sociedade, além do envolvimento em maior ou menor escala entre os povos de determinada região. Talvez pelo envolvimento do ser humano com um objeto que envolve sua própria vida e seu modo de ser, seja este 
um dos vários porquês da diversidade encontrada em um mundo cada vez mais próximo quanto o mundo globalizado. Fato também relevante é que a questão da cultura está cada vez mais mediada pelas tecnologias e veículos de comunicação, principalmente os de caráter massivo.

A cultura de massa aparece, portanto, em nossa contemporaneidade. Conforme se percebe na definição acima, ela se evidencia e se diferencia pela presença da mídia como agente difusor e mediador dos valores culturais de uma determinada sociedade, localidade ou região. A cultura de massa é um dos elementos que possibilitam nossa atual estrutura social; trata-se de um verdadeiro amálgama que unifica uma propensão do ser humano a compor-se enquanto consumidor da produção midiática, ou a posicionar-se enquanto tal.

Os estudos sobre os veículos de comunicação de massa e sua inserção na sociedade contemporânea, bem como os efeitos causados perante o desenvolvimento da tecnologia de comunicação, passaram a ganhar força a partir do momento em que se constataram a importância econômica, social, política e ideológica do fenômeno comunicacional.

Para Luiz Costa Lima, o processo de comunicação de massa apenas se instituiu na sociedade contemporânea a partir do momento em que três fatores preponderantes se associaram: "(a) base tecnológica; (b) sistema social que a utiliza; (c) cultura de massa" (LIMA, 1990, p.44). Fenômeno circunscrito apenas a partir do século XX (CAMPOS, 2006a, p.139).

Desse modo se percebe a importância do fator tecnologia, que originou o desenvolvimento e implantação dos veículos de comunicação de massa. "De modo geral, faz-se presente até os dias atuais, onde os veículos de comunicação de massa assumem papéis preponderantes no direcionamento de comportamentos, moda e consumo das massas" (CAMPOS, 2006a, p.139).

A disseminação da sociedade baseada na economia de mercado, e o próprio processo de desenvolvimento do capitalismo como um todo, encarregaram-se de fornecer as bases para o sistema social atualmente vigente. Uma sociedade que se organiza no sentido do consumo, e por este é orientada de tal forma que utiliza as mensagens advindas dos veículos de comunicação de massa para estabelecer várias de suas relações nas suas vidas cotidianas.

Nesse sentido se perfaz a cultura de massa ilustrada por Luiz Costa Lima (Idem, p.39): não bastaram, portanto, a arrancada do sistema capitalista, o incremento da velocidade da comunicação, o aparecimento dos primeiros meios de reprodução técnica e a baixo preço para que já se desse a cultura de massa. Necessária se faz a integração inconsciente de suas mensagens em uma modalidade de cultura.

A abordagem dada por Luiz Costa Lima deixa de vislumbrar as características e processos inerentes aos mass media no século XXI, porém, não é por isso, defasada. Pelo contrário, o modelo apresentado pelo autor em 1990 apenas teve seu processo acentuado na atualidade.

As novas tecnologias de comunicação apresentam-se como uma das bases que possibilitam ao ser humano o fenômeno da globalização. Tais tecnologias decorrem do processo de digitalização e convergência das mídias para um suporte computadorizado que, por sua vez, desempenha um papel preponderante nas comunicações globais. Mais explicitamente se pode citar a internet, a televisão digital, a telefonia celular e a possibilidade de transmissão via satélite e fibras óticas. Claro está o papel preponderante dessas novas tecnologias dentro deste processo (CAMPOS, 2006a, p.140).

Conforme salientado pelo autor, o processo de globalização procedeu de modo a evidenciar e acentuar o fenômeno da cultura de massa, ou ainda reforçar a presença da mídia em nosso cotidiano. Daí a importância de se estudar as mediações estabelecidas 
a partir da produção midiática - neste caso, o cinema e algumas produções cinematográficas previamente selecionadas, como forma de entender aspectos que demonstrem interfaces culturais no decorrer da narrativa filmica.

\section{O Conceito de CUlTura da Mídia}

A partir do desenvolvimento apresentado pelos veículos de comunicação de massa e sua interação com a sociedade, de modo a gerar uma grande influência, percebeu-se a necessidade de desenvolver-se estudos teóricos que pontuassem o tamanho e os porquês de tal intervenção. Foi assim que, a partir do início do século $\mathrm{XX}$, várias correntes ligadas à teoria da comunicação frutificaram. Neste artigo, propõe-se o foco no conceito de cultura da mídia sugerido pelo norte-americano Douglas Kellner, como conceito e posicionamento adotado a priori para análise da interface mídia e cultura.

Um aspecto que se evidencia na obra de Kellner ao instaurar a definição de cultura da mídia é o resgate de um outro conceito, de viés crítico, estabelecido por uma corrente teórica que, na área de comunicação de massa, ficou conhecida como Escola de Frankfurt, caracterizada especialmente por sua crítica ao processo de produção cultural sob a égide do sistema e modo capitalista. Trata-se do conceito de Indústria Cultural. Este foi desenvolvido por dois autores frankfurtianos: Max Horkheimer e Theodor Adorno, em 1947, conforme se evidencia na citação a seguir:

O termo Indústria Cultural foi originalmente concebido por Theodor Adorno (1903/1969) e Max Horkheimer (1895/1973), autores do livro $A$ Dialética do Esclarecimento, publicado em 1947. Trata-se de um conceito que evidencia um viés crítico da sociedade de massas sob o contexto da corrente teórica da comunicação que ficou conhecida como "Escola de Frankfurt" (Teoria Crítica). Deve-se esta denominação ao início de seus trabalhos no Instituto de Pesquisa Social, criado em 03/02/1923, vinculado à Universidade de Frankfurt. Do qual Max Horkheimer assumiu a direção após 1930, dedicando-se a uma análise questionadora dos valores do capitalismo moderno (CAMPOS, 2006b, p.106).

Através da definição de Indústria Cultural, os teóricos da Escola de Frankfurt evidenciavam que a produção artística e cultural na atualidade é organizada sob moldes das relações capitalistas, fato que atende aos padrões sociais, ideológicos e econômicos de tal regime e o reproduz. Assim, a produção cultural do ser humano se transforma em mercadoria e se adapta aos moldes da economia de mercado. Todo este processo é chamado de Indústria Cultural e serve, segundo os teóricos evidenciados, como uma forma de dominação e perpetuação do regime capitalista e sua forma de dominação.

Os teóricos da Escola de Frankfurt sofreram críticas por seu posicionamento extremamente contrário à produção cultural inserida nos moldes contemporâneos de produção e adaptados às tecnologias disponíveis na atualidade. As críticas advêm de um posicionamento um tanto quanto rigoroso adotado por eles e depois questionado por correntes teóricas que se desenvolveram adiante. A principal evidência passível de crítica posterior no conceito de Indústria Cultural é que nem tudo é dominação econômica e cultural, nem sempre as atitudes adotadas pelos veículos de comunicação de massa determinam e estabelecem os mecanismos de dominação.

Um dos questionamentos básicos para a produção teórica em comunicação seria como traçar um viés crítico às produções midiáticas na pósmodernidade sem incorrer em um posicionamento polarizado como a dos frankfurtianos em relação à indústria cultural. Faz-se necessário, então, perceber como um conceito advindo de uma escola de tradição marxista se faz tão presente em nossa realidade impregnada pelas regras de mercado (...) A cultura da mídia produzida e direcionada às massas é, portanto, fruto de uma Indústria Cultural estabelecida através de grandes 
conglomerados de comunicação e formatada através de suportes tecnológicos cada vez mais sofisticados. Entretanto, Kellner chama atenção para este fator multifacetário, não se pode se restringir ao antigo discurso entre direita e esquerda. Socialismo e capitalismo não mais embatem entre si na disputa política e ideológica. Ao contrário, percebe-se uma incorporação dos discursos progressistas e conservadores no cenário midiático. Os meios de comunicação de massa passam a ser o palco de discussões e tendências sociais, produz-se a socialização, rivaliza-se com outras instituições sociais tradicionais deste cenário, mas também se produzem questionamentos (LESSA, 2004, p.10).

A forte presença dos meios de comunicação de massa no cotidiano das pessoas acontece a partir da ocupação do tempo livre dos indivíduos com atividades que os distanciem do trabalho. À medida que as massas se predispõem a disponibilizar maior parte de seu tempo às atividades midiáticas aumenta o valor, em termos de importância, e a influência dos veículos de comunicação de massa na sociedade contemporânea. Tal influência e penetração determinam o modo de vida atual em que muitos autores pontuam como a sociedade do espetáculo, o planeta mídia e outras definições que demonstram a transformação do mundo e da produção cultural em uma espécie de matriz midiática, ou seja, envolvida e dependente da produção cultural mediada pelos veículos de comunicação de massa.

À medida que a importância do trabalho declina, o lazer e a cultura ocupam cada vez mais o foco da vida cotidiana e assumem um lugar significativo. Evidentemente, devemos trabalhar para auferir os benefícios da sociedade de consumo (ou para herdar riquezas suficientes), mas supõe-se que o trabalho esteja declinando em importância numa era em que, segundo se alega, os indivíduos obtêm mais satisfação do consumo de bens e das atividades de lazer do que das atividades laboriosas (KELLNER, 2001, p.29).
O posicionamento adotado por Kellner, ao propor o conceito de cultura da mídia, não parte de uma questão ingênua de negar os processos de dominação e exercício da ideologia dominante. Ao contrário, o autor admite e considera o fator de manipulação a partir da mídia.

Na última década também surgiram novas tecnologias que mudaram os padrões da vida cotidiana e reestruturaram poderosamente o trabalho e o lazer. As novas tecnologias do computador substituíram muitos empregos e criaram muitos novos, oferecendo novas formas de acesso à informação e à comunicação com outras pessoas e propiciando as alegrias de uma nova esfera pública informatizada. As novas tecnologias da mídia e da informática, porém, são ambíguas e podem ter efeitos divergentes. Por um lado, proporcionam maior diversidade de escolha, maior possibilidade de autonomia cultural e maiores aberturas para intervenções de outras culturas e ideias. No entanto, também propiciam novas formas de vigilância e controle, em que os olhos e sistemas eletrônicos instalados em locais de trabalho funcionam como encarnação do Grande Irmão. As novas tecnologias da mídia também propiciam poderosas formas de controle social por meio de técnicas de doutrinação e manipulação mais eficientes, sutis e ocultas. $\mathrm{Na}$ verdade, sua simples existência já cria a possibilidade de minar as energias políticas e de manter as pessoas bem guardadas dentro dos confins de seus centros de entretenimento doméstico, distante do tumulto das multidões e dos locais de ação política de massa (...) Enquanto a cultura da mídia, em grande parte, promove os interesses das classes que possuem e controlam os grandes conglomerados dos meios de comunicação, seus produtos também participam dos conflitos sociais entre grupos concorrentes e veiculam posições conflitantes, promovendo, às vezes, forças de resistência e progresso. Consequentemente, a cultura veiculada pela mídia 
não pode ser simplesmente rejeitada como um instrumento banal da ideologia dominante, mas deve ser interpretada e contextualizada de modos diferentes dentro da matriz dos discursos e das forças sociais concorrentes que a constituem (KELLNER, 2001, p. 26,27).

Para explicar melhor esse posicionamento teórico, cabe salientar que Kellner vislumbra a presença dos veículos de comunicação de massa na sociedade contemporânea como um palco midiático onde acontecem as discussões sociais em termos de exercício da hegemonia e da resistência, grupos sociais que, através da mídia, conseguem veicular suas produções que ora são extremamente críticas ao sistema estabelecido, ora estão altamente integradas ao processo de dominação. Tais possibilidades acontecem em razão de os veículos de comunicação de massa estarem em constante busca pela audiência e, a partir desta necessidade, abrirem espaços para vários posicionamentos, inclusive das minorias sociais.

Muitos críticos propuseram com correção que o conceito de ideologia se estendesse e passasse a abranger teorias, ideias, textos e representações que legitimem interesses de forças dominantes em termos de sexo e raça, bem como de classe. Dessa perspectiva, fazer crítica da ideologia implica criticar ideologias sexistas, heterossexistas e racistas tanto quanto a ideologia da classe burguesa capitalista. Tal crítica da ideologia é multicultural, discernindo um espectro de formas de opressão de pessoas de diferentes raças, etnias, sexo e preferência sexual e traçando os modos como as formas e os discursos culturais ideológicos perpetuam a opressão. A crítica multicultural da ideologia exige levar a sério as lutas entre homens e mulheres, feministas e antifeministas, racistas e antirracistas, gays e antigays, além de muitos outros conflitos, que são considerados tão importantes e dignos de atenção quanto os conflitos de classe o são pela teoria marxista. Parte-se assim do pressuposto de que a sociedade é um grande campo de batalha, e que essas lutas heterogêneas se consumam nas telas e nos textos da cultura da mídia e constituem o terreno apropriado para um estudo crítico da cultura da mídia (KELLNER, 2001, p.79).

Em termos de aproximação e foco teórico referentes à cultura da mídia deve-se, portanto, eleger produções advindas de mídias específicas, no sentido de desenvolver um exercício de análise em termos de cultura da mídia de tais obras. Visa evidenciar os fatores ideológicos que constituem a construção do discurso e da narrativa dos produtos midiáticos. Por fim, ao se desenvolver tal exercício do conceito de cultura da mídia ter-se-á como foco demonstrar como tais produções ligadas ao lazer e ao entretenimento acabam por consolidar-se enquanto instrumentos de discussão de questões sociais no palco de debates contemporâneos que a mídia se tornou.

A análise das produções midiáticas deve focar as posições sociais, em termos de hegemonia e resistência e como são representadas no palco midiático. Tais posicionamentos podem mostrar-se bastante explícitos e realmente ilustrar pontos diferenciados em termos culturais e sociais perante a sociedade e através da mídia e da sua presença na sociedade atual.

A partir desse ponto, a pesquisa citada inicialmente será continuada. "O Conceito de Cultura da Mídia, Indústria Cultural e Produção de Entretenimento no Brasil-Sua empregabilidade através do caso Ônibus 174" propõe verificar a empregabilidade do conceito de Cultura da Mídia em produções fílmicas nacionais. Para tanto, sugere a aplicação de tal conceito perante a obra de José Padilha (documentário), Ônibus 174 (2003), e de Bruno Barreto, Última Parada 174 (2008) (filme-longa-metragem).

\section{REFERÊNCIAS}

ASSOCIAÇÃO BRASILEIRA DE NORMAS TÉCNICAS. NBR 6023: Informação e Documentação, Referências Elaboração. Rio de Janeiro: ABNT, 2002. 
NBR 10520: Informação e Documentação, Citações em Documentos, Apresentação. Rio de Janeiro: Agosto de 2002.

NBR 14724: Informação e

Documentação, Trabalhos Acadêmicos,

Apresentação. Rio de Janeiro: Dezembro de 2005.

CAMPOS, Renato Márcio Martins de. Indústria

Cultural e Cultura da Mídia: Produção e Distribuição do Entretenimento na Sociedade Global. Revista

Communicare. São Paulo, Vol. 6, n. ${ }^{\circ}$ 1, 2006a.

CAMPOS, Renato Márcio Martins de. Teorias da Comunicação: As Correntes Teóricas no Estudo da Comunicação de Massa. Revista Uniara. Araraquara, Vol.19, 2006 b.

KELLNER, Douglas. A Cultura da Mídia.
Bauru: Edusc, 2001.

LESSA, Maraisa B.; CAMPOS, Renato Márcio M. Indústria Cultural e Cultura da Mídia: Da Modernidade à Lógica Cultural Pós-Moderna. In: XXVII Intercom, 2004, Porto Alegre.

CONGRESSO DE CIÊNCIAS DA COMUNICAÇÃO, 27., Anais. http://reposcom.portcom.intercom.org.br/handle/ 1904/17275. Acesso em: 14 Jul. 2009.

MARTIN, Hans Peter; SCHUMANN, Harald. A Armadilha da Globalização. São Paulo: Globo, 1998.

ORTIZ, Renato. Mundialização e Cultura. São Paulo: Brasiliense, 2000.

SANTOS, Boaventura de Souza. A Globalização e as Ciências Sociais. São Paulo: Cortez, 2002.

RECEBIDO EM 29/10/2010

ACEITO EM 8/12/2010 